\title{
Pulmonary arterial wall disease in COPD and interstitial lung diseases candidates for lung transplantation
}

\author{
Enric Domingo ${ }^{1,2+}$, Juan C. Grignola ${ }^{3^{*}}$, Rio Aguilar ${ }^{4}$, Manuel López Messeguer ${ }^{5}$ and Antonio Roman ${ }^{5,6}$
}

\begin{abstract}
Background: Pulmonary hypertension (PH) associated with lung disease has the worst prognosis of all types of $\mathrm{PH}$. Pulmonary arterial vasculopathy is an early event in the natural history of chronic obstructive pulmonary disease (COPD) and interstitial lung disease (ILD). The present study characterized the alterations in the structure and function of the pulmonary arterial (PA) wall of COPD and ILD candidates for lung transplantation (LTX).

Methods: A cohort of 73 patients, 63 pre-LTx (30 COPD, 33 ILD), and ten controls underwent simultaneous right heart catheterisation and intravascular ultrasound (IVUS). Total pulmonary resistance (TPR), capacitance (Cp), and the TPR-Cp relationship were assessed. PA stiffness and the relative area of wall thickness were estimated as pulse PA pressure/IVUS pulsatility and as [(external sectional area-intimal area)/external sectional area] $\times 100$, respectively.

Results: Twenty-seven percent of patients had pulmonary arterial wedge pressure $>15 \mathrm{mmHg}$ and were not analyzed. PA stiffness and the area of wall thickness were increased in comparison with controls, even in patients without PH $(p<0.05)$. ILD patients showed a significant higher PA stiffness, and lower $\mathrm{Cp}$ beyond mean PA pressure (mPAP) and lower area of wall thickness than COPD patients $(p<0.05)$. TPR-Cp relationship was shifted downward left for ILD patients.

Conclusions: Significant increase of PA stiffness and area of wall thickness were present even in patients without $\mathrm{PH}$ and can make the diagnosis of pulmonary vasculopathy at a preclinical stage in $\mathrm{PH}$-lung disease candidates for LTX. ILD patients showed the worst PA stiffness and Cp with respect to COPD.
\end{abstract}

Keywords: Pulmonary hypertension, Lung transplantation, Pulmonary arterial wall, Chronic obstructive pulmonary disease, Interstitial lung disease

\section{Background}

Pulmonary hypertension $(\mathrm{PH})$ is a well-recognized complication of chronic obstructive pulmonary disease (COPD) and interstitial lung disease (ILD) that impacts on the functional capacity, the risk of hospitalization, and survival [1]. PH associated with lung disease has the worst prognosis of all types of $\mathrm{PH}$ [2]. The prevalence of $\mathrm{PH}$ in both chronic lung diseases depends on the severity of the disease and the definition and methodologies used in the studies $[3,4]$. Most of the available data

\footnotetext{
* Correspondence: jgrig@fmed.edu.uy

${ }^{\dagger}$ Equal contributors

${ }^{3}$ Pathophysiology Department, School of Medicine, Hospital de Clínicas, Universidad de la República, Avda Italia 2870, PC 11600 Montevideo, Uruguay

Full list of author information is available at the end of the article
}

regarding $\mathrm{PH}$-lung disease comes from patients undergoing evaluation for lung transplantation (LTx). In a recent cohort of 362 patients with severe COPD who were evaluated for LTx and underwent right heart catheterization, the prevalence of pre-capillary $\mathrm{PH}$ was $23 \%[5,6]$. PH may complicate the course of many forms of ILD [7, 8]. The prevalence of PH for idiopathic pulmonary fibrosis (IPF), the most frequent of ILD disease, is between 10 to $80 \%$ [9-11].

The relation between the severity and extent of pulmonary vascular disease and the degree of hemodynamic abnormalities seen in PH-lung disease is poorly understood [1]. Recently, the analysis of pulmonary arterial lesions in explanted lungs of COPD patients demonstrated that histological pulmonary vascular changes are 
prevalent, including lesions Grade 3 (Heath \& Edwards) even in patients without $\mathrm{PH}$ [12]. The analysis of the United Network for Organ Sharing database showed that an increase in the mean pulmonary arterial pressure (mPAP) from the time of wait listing to the time of LTx was associated with poorer survival in patients with COPD and ILD after LTx even in the lung allocation scoring era $[6,13]$. Therefore, the early diagnosis of pulmonary vascular disease and PH in COPD and ILD candidates for LTx could have an impact on survival.

We hypothesized that pulmonary vascular disease is present even with normal resting MPAP and would be related to the hemodynamic and parenchymal disease severity (obstructive/restrictive impairment) in COPD and ILD candidates for LTx. The first aim of the present study is to assess and to compare the extent of functional (pulmonary artery stiffness, PAS) and anatomical (area of wall thickness, AWT) pulmonary vascular disease in COPD and ILD candidates for LTx according to the hemodynamic severity. The second aim was to correlate the pulmonary arterial vasculopathy with the severity of airway and parenchymal lung impairment in COPD and ILD candidates for LTx, respectively.

\section{Methods}

\section{Study design}

A cohort of 63 consecutive adult subjects candidates for LTx for COPD $(n=30)$ and ILD $(n=33)$ between January 2011 and December 2012 was included. All patients were studied as potential candidates for lung transplantation according to the International Society for Heart and Lung Transplantation guidelines [14]. Evaluation included clinical and laboratory examination, chest X-ray imaging, pulmonary function tests (forced expiratory volume in one second, FEV1; the forced vital capacity, FVC; diffusion capacity for carbon monoxide, DLCO), electrocardiography, 6-min walk test (6MWT), Doppler echocardiography, and highresolution computed tomography imaging. All patients underwent a routine right heart catheterization and simultaneous medium-sized elastic pulmonary arteries intravascular ultrasound (IVUS) in the supine position and breathing room air.

The patients were compared with ten control subjects referred for cardiac catheterization due to clinically suspected $\mathrm{PH}$, and in whom $\mathrm{PH}$ and other respiratory and cardiovascular diseases were discarded. $\mathrm{PH}$ was defined as mPAP greater or equal than $25 \mathrm{mmHg}$.

The study complied with the Declaration of Helsinki and the study protocol was approved by the Institutional Ethics Committee of the Hospital Universitari Vall d'Hebron (Barcelona). Written informed consent was obtained from all patients.

\section{Hemodynamic and IVUS studies}

A $7 \mathrm{~F}$ Swan-Ganz catheter was inserted into a brachial vein, and a $5 \mathrm{~F}$ end-hole catheter was inserted into the right radial artery to monitor systemic arterial pressure. Both catheters were connected to pressure transducers. The zero reference level for recording was at midthoracic level [15]. An electrocardiogram and heart rate were recorded continuously, and cardiac output (CO) was assessed using the indirect Fick method. Resting oxygen uptake was calculated by the formula of Dehmer, based on body surface area (BSA) $\left(125 \mathrm{~mL} / \mathrm{min} / \mathrm{m}^{2} \times\right.$ BSA) [16]. All pressures, including right atrial pressure (RAP), mPAP and pulmonary arterial wedge pressure (PAWP), were taken in the supine position and at endexpiration [17]. We calculated pulmonary vascular resistance (PVR) and total pulmonary resistance (TPR) as (mPAP-PAWP)/CO and $\mathrm{mPAP} / \mathrm{CO}$, respectively. Total pulmonary arterial capacitance $(\mathrm{Cp})$ was estimated by the stroke volume/pulse PAP ratio [18]. We discarded the patients with PAWP $\geq 15 \mathrm{mmHg}$. We estimated pulmonary arterial $\mathrm{RC}$ time as the product of resistance and capacitance $(\mathrm{PVR} \times \mathrm{Cp})$. We examined the relationship between TPR and $\mathrm{Cp}$ to analyze the consequences of pulmonary vascular disease to the dynamic afterload [19]. To compare the TPR-Cp relationship for each group, the TPR, and CP data were logarithmically transformed and plotted on a linear axis.

IVUS examination was performed with an Opticross imaging catheter $40 \mathrm{MHz}, 3.1 \mathrm{~F}$ (Boston Scientific Corporation, USA) with an axial resolution of $38 \mu \mathrm{m}$. A minimum of three representative images were obtained from segmental pulmonary arteries (elastic pulmonary artery $\sim 2-3 \mathrm{~mm}$ of diameter) $[20,21]$ and stored in digital form. Both diastolic and systolic cross-sectional areas of the studied segment were analyzed off-line by two observers unaware of clinical and hemodynamic findings. We estimated IVUS pulsatility (IVUSp) as (systolicdiastolic lumen area)/diastolic lumen area $\times 100$. PAS was assessed by the elastic modulus (EM) or pressure/elastic strain index (pulse PAP/IVUSp), an expression of the intrinsic pulmonary arterial wall viscoelastic properties [22]. Intra- and inter-observer validation of IVUS measurements in our laboratory have been previously published [20,21]. Because of the strong dependency of strain on underlying pressures, we compared $\mathrm{Cp}$ and EM of both groups according to mPAP [22]. Finally, we calculated the relative AWT as (external sectional area-intimal area)/external cross-sectional area $\times 100$ [23].

\section{Statistical analysis}

Continuous variables are expressed as mean \pm SEM. Categorical variables were summarized by frequency. Independent sample t-tests were used to compare differences between the control, COPD and ILD patients. Chi-squared 
Table 1 Demographic, anthropometric, clinical, and pulmonary function data in control subjects and patients with COPD and ILD

\begin{tabular}{|c|c|c|c|}
\hline & $\operatorname{COPD}(n=18)$ & ILD $(n=28)$ & Control $(n=10)$ \\
\hline Age, years & $58 \pm 1^{*}$ & $58 \pm 2^{*}$ & $51 \pm 2$ \\
\hline Sex, M/F & $17 / 1^{*}$ & $18 / 10^{*} \S$ & $4 / 6$ \\
\hline $\mathrm{BMI}, \mathrm{kg} / \mathrm{m}^{2}$ & $25.0 \pm 1.4$ & $26.3 \pm 0.8$ & $23.6 \pm 1.2$ \\
\hline $\mathrm{FC}\|/\| / \| / I V, \%$ & $0 / 78 / 22$ & 14/79/7 & \\
\hline $6 \mathrm{MWT}$, meters & $300 \pm 22$ & $315 \pm 15$ & \\
\hline FVC, L & $1.8 \pm 0.2$ & $1.9 \pm 0.14$ & \\
\hline FVC, \% predicted & $44 \pm 3$ & $50 \pm 3$ & \\
\hline FEV1, L & $0.77 \pm 0.08$ & $1.56 \pm 0.13 \S$ & \\
\hline FEV1, \% predicted & $24 \pm 2$ & $58 \pm 3 \S$ & \\
\hline FEV1/FVC & $0.42 \pm 0.03$ & $0.82 \pm 0.03 \S$ & \\
\hline DLCO, \% predicted & $33 \pm 5$ & $27 \pm 2 \S$ & \\
\hline FVC\%/DLCO\% & $1.5 \pm 1.0$ & $2.6 \pm 0.3 \S$ & \\
\hline $\mathrm{PaO}_{2}, \mathrm{~mm} \mathrm{Hg}$ & $64 \pm 2.3$ & $62 \pm 2.4$ & \\
\hline $\mathrm{PaCO}_{2}, \mathrm{~mm} \mathrm{Hg}$ & $50 \pm 2.3$ & $40 \pm 1.4 \S$ & \\
\hline
\end{tabular}

\section{Data are mean \pm SEM}

Abbreviations: $B M I$ body mass index, 6MWT 6-min walking test, DLCO diffusion capacity of the lung for carbon monoxide, FC functional class, FEV1 forced expiratory volume in one second, FVC forced vital capacity, $\mathrm{PaO}_{2}$ and $\mathrm{PaCO}_{2}$ partial arterial pressure of oxygen and dioxide of carbon, respectively ${ }^{*} p<0.05$ vs. Control; $\S p<0.05$ vs. COPD

was used for comparing proportions of patients. Intergroup variation was analyzed using one-way ANOVA.

The association between vascular remodeling (EM and AWT), hemodynamic impairment and lung functional tests were explored using linear regression analysis
(Pearson coefficient). A two-sided $P$ value $<0.05$ was regarded as significant. Data analysis were carried out using SPSS 17.0 for Windows 7 software.

\section{Results}

Twenty-seven percent of patients had PAWP > $15 \mathrm{mmHg}$ $(n=17)$ and were excluded. Pre-capillary $\mathrm{PH}$ was presented in $44 \%$ of COPD (8/18) and $46 \%$ of ILD (13/28). COPD and ILD patients presented an unimodal distribution with a mean of $26 \pm 2$ and $27 \pm 2 \mathrm{mmHg}$, respectively, indicating that $\mathrm{PH}$ was mainly mild to moderate when present.

Baseline demographics, clinical data, and pulmonary function test were shown in Table 1 . Both, COPD and ILD patients were older than the control group $(p<0.05)$. The proportion of women was $5 \%$ in COPD, 36\% in ILD and $60 \%$ in Controls $(p<0.05)$. However, body mass index was not different between the groups. The aetiologies of ILD correspond to Idiopathic Pulmonary Fibrosis (61\%); Idiopathic non-Specific Interstitial Pneumonitis (10\%); Connective Tissue Disease-related ILD (10\%) and others (19\%) [24].

Both, functional class and 6MWT showed no differences between COPD and ILD patients. All patients showed relative hypoxemia with normo (ILD) or hypercapnia (COPD). Both groups showed a severely reduced FVC, and DLCO had higher impairment in ILD than in COPD patients $(p<0.05)$, with out of proportion to the reduction in lung volume (FVC\%/DLCO\%). $\mathrm{PH}$ patients walked less than non-PH patients (COPD: $288 \pm 28$ versus $307 \pm 34 \mathrm{~m}$; and ILD: $280 \pm 16$ versus $345 \pm 22 \mathrm{~m}$ ), although only in ILD group reached to statistical significance. $\mathrm{PH}$ patients presented significant lower partial

Table 2 Hemodynamic and IVUS data in control subjects and patients with COPD and ILD with or without pulmonary hypertension

\begin{tabular}{|c|c|c|c|c|c|c|c|}
\hline & \multicolumn{3}{|c|}{ Chronic Obstructive Pulmonary Disease } & \multicolumn{3}{|c|}{ Interstitial Lung Disease } & \multirow{2}{*}{$\begin{array}{l}\text { Control } \\
(10)\end{array}$} \\
\hline & All (18) & Non PH (10) & $\mathrm{PH}(8)$ & All (28) & Non PH (15) & $\mathrm{PH}(13)$ & \\
\hline $\mathrm{mPAP}, \mathrm{mm} \mathrm{Hg}$ & $26 \pm 2^{*}$ & $21 \pm 1^{*}$ & $33 \pm 3^{*} \#$ & $27 \pm 2^{*}$ & $20 \pm 1^{*}$ & $32 \pm 3^{*}$ & $15 \pm 2$ \\
\hline $\mathrm{pPAP}, \mathrm{mm} \mathrm{Hg}$ & $16 \pm 2^{*}$ & $14 \pm 1$ & $18 \pm 3^{*}$ & $23 \pm 2 * \S$ & $17 \pm 0.9^{*}$ & $27 \pm 4^{*} \# \S$ & $11 \pm 3$ \\
\hline $\mathrm{Cl}, \mathrm{L} / \mathrm{min} / \mathrm{m}^{2}$ & $2.5 \pm 0.2$ & $2.3 \pm 0.2^{*}$ & $2.5 \pm 0.2$ & $2.5 \pm 0.1$ & $2.5 \pm 0.1$ & $2.5 \pm 0.1$ & $2.6 \pm 0.1$ \\
\hline $\mathrm{HR}, \mathrm{bpm}$ & $76 \pm 3$ & $72 \pm 4$ & $82 \pm 4.4$ & $81 \pm 2.6$ & $80 \pm 4$ & $83 \pm 3$ & $73 \pm 1.3$ \\
\hline $\mathrm{SV}, \mathrm{mL}$ & $57 \pm 2$ & $54 \pm 3$ & $56 \pm 4$ & $60 \pm 2$ & $61 \pm 3$ & $59 \pm 3$ & $64 \pm 2$ \\
\hline $\mathrm{RAP}, \mathrm{mm} \mathrm{Hg}$ & $8.7 \pm 0.7^{*}$ & $7.4 \pm 0.7^{*}$ & $10.8 \pm 1.2^{*} \#$ & $5.4 \pm 0.6 \S$ & $5.2 \pm 0.8$ & $6.1 \pm 0.4 \S$ & $5.0 \pm 1.2$ \\
\hline PAWP, mm Hg & $10.9 \pm 0.7$ & $10.0 \pm 1.0$ & $11.6 \pm 0.7^{*}$ & $8.0 \pm 0.5 \S$ & $7.7 \pm 0.8$ & $9.0 \pm 0.8 \S$ & $8.8 \pm 0.6$ \\
\hline PVR, Wu & $3.3 \pm 0.3$ & $2.9 \pm 1.3$ & $3.9 \pm 0.5^{*}$ & $4.1 \pm 0.4^{*}$ & $2.9 \pm 0.4$ & $5.6 \pm 0.4^{*} \S \#$ & $3.0 \pm 0.3$ \\
\hline TPR, Wu & $6.3 \pm 0.6^{*}$ & $5.8 \pm 0.6^{*}$ & $7.1 \pm 1.1^{*}$ & $6.2 \pm 0.5^{*}$ & $4.7 \pm 0.4^{*}$ & $8.2 \pm 0.6^{*} \#$ & $3.3 \pm 0.25$ \\
\hline $\mathrm{Cp}, \mathrm{mL} / \mathrm{mmHg}$ & $4.2 \pm 0.28^{*}$ & $4.3 \pm 0.3^{*}$ & $3.0 \pm 0.7^{*} \#$ & $2.9 \pm 0.2^{*} \S$ & $3.5 \pm 0.2^{*}$ & $2.1 \pm 0.1 * \S$ & $6.2 \pm 0.4$ \\
\hline RC time, sec & $0.8 \pm 0.05^{*}$ & $0.67 \pm 0.06^{*}$ & $0.98 \pm 0.1^{*} \#$ & $0.6 \pm 0.02 * \S$ & $0.55 \pm 0.04^{*}$ & $0.69 \pm 0.07^{*} \#$ & $1.1 \pm 0.03$ \\
\hline $\mathrm{EM}, \mathrm{mm} \mathrm{Hg}$ & $64 \pm 5^{*}$ & $51 \pm 5^{*}$ & $79 \pm 9 * \#$ & $105 \pm 7^{*} \S$ & $90 \pm 7^{*} \S$ & $124 \pm 11^{*} \S \#$ & $21 \pm 1.7$ \\
\hline AWT, \% & $23 \pm 1^{*}$ & $19 \pm 1^{*}$ & $24 \pm 1^{*}$ & $17 \pm 1^{*} \S$ & $18 \pm 1^{*}$ & $15 \pm 1$ *§\# & $1.4 \pm 1.3$ \\
\hline
\end{tabular}

Data are mean \pm SEM

Abbreviations: $A W T$ area wall thickness, $C l$ cardiac index, $C p$ total pulmonary arterial capacitance, $E M$ elastic modulus, $H R$ heart rate, $m P A P$ and $p P A P$ mean and pulsatile pulmonary arterial pressure, respectively, $P A W P$ pulmonary arterial wedge pressure, $P V R$ pulmonary vascular resistance; SV: stroke volume, RAP right atrial pressure, TPR total pulmonary resistance

${ }^{*} p<0.05$ vs. Control; $\S p<0.05$ vs. COPD; $\# p<0.05$ vs. Non $\mathrm{PH}$ 
pressure of arterial oxygen $\left(\mathrm{PaO}_{2}\right)$ than non- $\mathrm{PH}$ patients (COPD: $59 \pm 2$ versus $65 \pm 2 \mathrm{mmHg}$; and ILD: $57 \pm 2$ versus $66 \pm 2 \mathrm{mmHg}$ ). Both, FEV1 in COPD patients, and FVC in ILD patients did not show significant differences between $\mathrm{PH}$ and non-PH patients.

\section{Pulmonary hemodynamics and pulmonary arterial wall disease in COPD and ILD}

ILD patients showed significantly higher pulse PAP and lower $\mathrm{Cp}$ than in COPD patients, in spite of similar mPAP, which is in relation with a lower $\mathrm{RC}$ time (Table 2).

Figure 1 showed the values of EM and AWT of COPD and ILD patients, which were significantly higher than controls, while ILD patients showed a significant higher EM and lower AWT than COPD patients $(p<0.05)$. All except one preLTx COPD patient presented higher EM (COPD: 22 to $124 \mathrm{mmHg}$; ILD: 33 to $210 \mathrm{mmHg}$ ) and AWT (COPD: 13 to 34; ILD: 5 to 31) than control subjects (EM: 12 to $30 \mathrm{mmHg}$ and AWT: 1 to 4). Among the non-PH patients, $7 / 10$ (COPD) and 10/15 (ILD) patients had a mPAP between $21-24 \mathrm{mmHg}$.

Figure 2 displays the hyperbolic relationship of TPR and $\mathrm{Cp}$ of both groups, showing that TPR-Cp curve is shifted downward left for ILD, with a reduced Cp value for a given TPR. The logarithmically transformed TPR$\mathrm{Cp}$ plot showed that the slope of the linear regression for ILD and COPD were -1 and -0.8 respectively, indicating that TPR and Cp are tightly and inversely coupled in both groups of patients.

Mean diameter of the pulmonary arteries studied was similar among the different groups (COPD: $1.84 \pm 1.3 \mathrm{~mm}$; ILD: $2.03 \pm 1.2 \mathrm{~mm}$; controls: $1.91 \pm 1.1 \mathrm{~mm}$ ).

\section{Relationship between the severity of pulmonary} hemodynamic and pulmonary arterial wall disease

Table 2 summarizes the hemodynamic and IVUS data for the patients with or without PH. Patients without $\mathrm{PH}$ of both groups showed a significant increased EM and AWT to control non-PH patients, which is
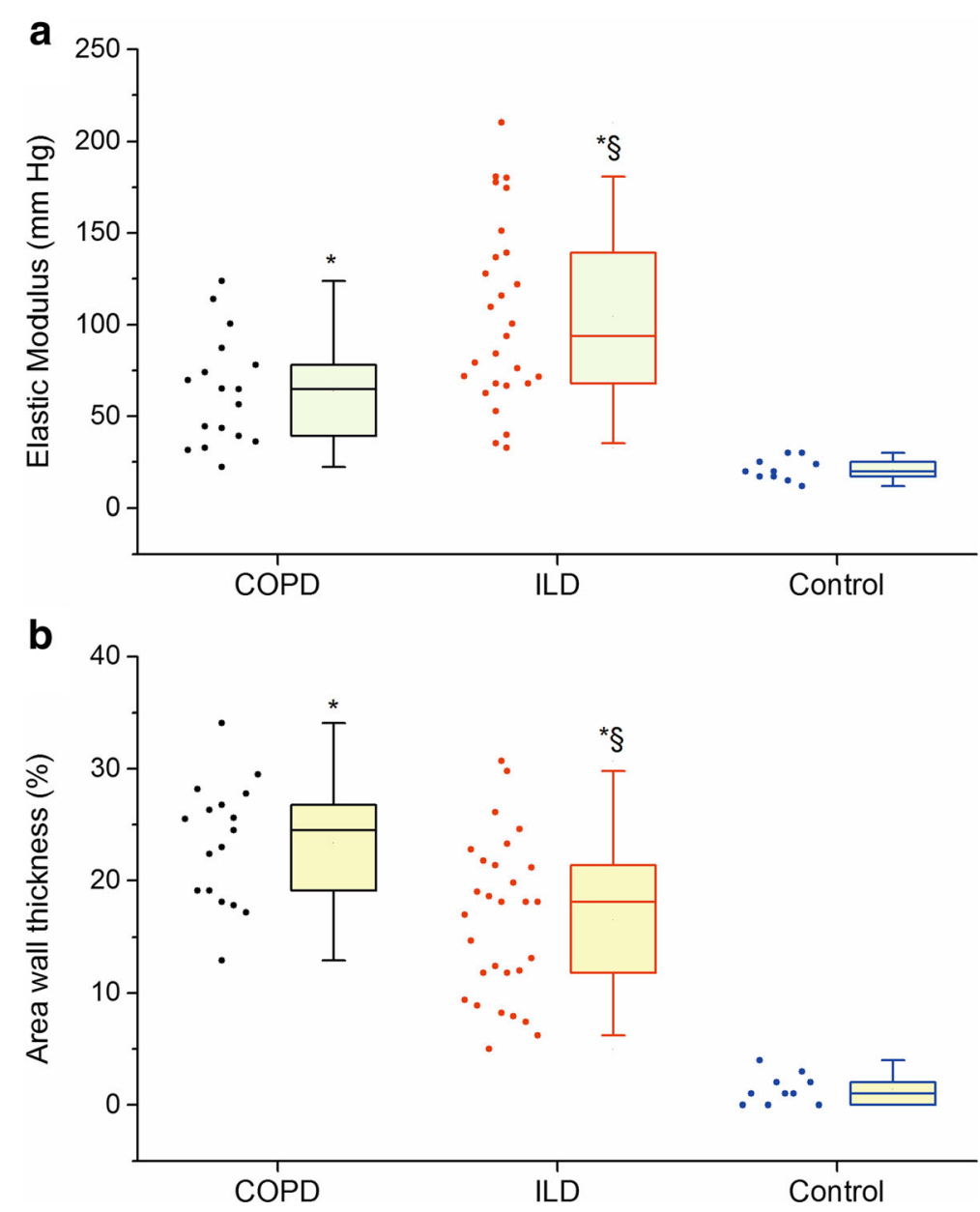

Fig. 1 Box plots (median and percentiles 25/75) of Elastic Modulus a and area wall thickness $\mathbf{b}$ among the different groups. ${ }^{*} p<0.05$ vs. Control. $\S p<0.05$ vs. COPD 

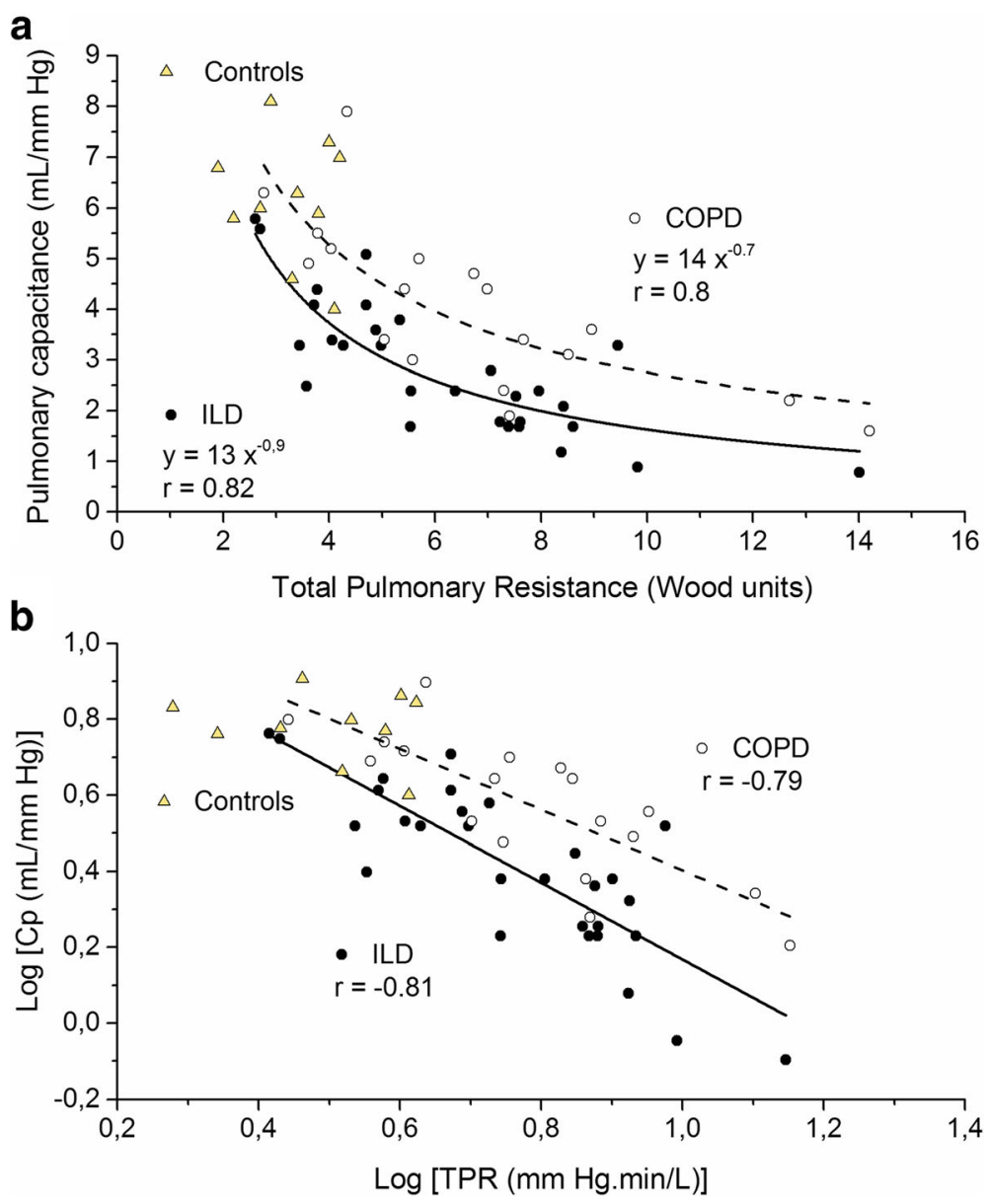

Fig. 2 a Inverse relationship of Cp-TPR relationship and $\mathbf{b}$ Log TPR-log Cp plot. Both curves showed that ILD patients are shifted left downward

associated with a higher MPAP and TPR and lower $\mathrm{Cp}$ and $\mathrm{RC}$ time $(p<0.05)$.

In COPD, both EM $(r=0.66, p<0.01)$ and AWT $(r=0.6$, $p<0.05)$ correlated with mPAP. By contrast, in ILD only EM $(r=0.63, p<0.01)$ worsened with increasing mPAP. Both, Cp $(r=-0.66, p<0.01)$ and PVR $(r=0.43, p<0.05)$ were correlated with EM in COPD. On the contrary, in ILD group, only PVR correlated with EM $(r=0.38, p<0.05)$. Figure $3 \mathrm{a}$ and $\mathrm{b}$ show the dependence of the $\mathrm{Cp}$ and EM to the working mPAP in both groups. ILD patients showed lower $\mathrm{Cp}$ and higher EM than COPD, either in $\mathrm{PH}$ as non$\mathrm{PH}$ patients.

\section{Relationship between lung function impairment and pulmonary hemodynamics and arterial wall disease in COPD and ILD}

Both, COPD and ILD patients showed that $\mathrm{PaO}_{2}$ was correlated with mPAP (COPD: $r=-0.44, p<0.01$; ILD: $r=-0.35$, $p<0.02$ ) and EM (COPD: $r=-0.35, p<0.01$; ILD: $r=-0.43$, $p<0.01)$. Only in COPD, partial pressure of carbon dioxide was correlated with mPAP $(r=0.37)$ and EM $(r=0.55)$ $(p<0.05)$. Figure 4 showed that only in COPD, EM and not mPAP, correlated to lung function impairment (FEV1).

\section{Discussion}

We analyze the pulmonary vascular disease in candidates for LTx with advanced COPD and ILD. We have identified several issues having potential clinical relevance: (1) moderate to severe pulmonary vascular disease is present in almost all patients, even without $\mathrm{PH}$ and is related to hemodynamic severity; (2) patients with advanced COPD and ILD seem to have different pulmonary vascular disease; and (3) EM is related to the severity of airflow limitation in COPD patients.

\section{Pulmonary hemodynamics and pulmonary arterial wall disease in COPD and ILD patients}

In the present cohort of advanced COPD and ILD preLTx patients, the prevalence of pre-capillary $\mathrm{PH}$ was $44 \%$ for COPD and $46 \%$ for ILD. This is in agreement with single center reports and the United Network for Organ Sharing database $[6,10,25]$. We found $27 \%$ of patients with 

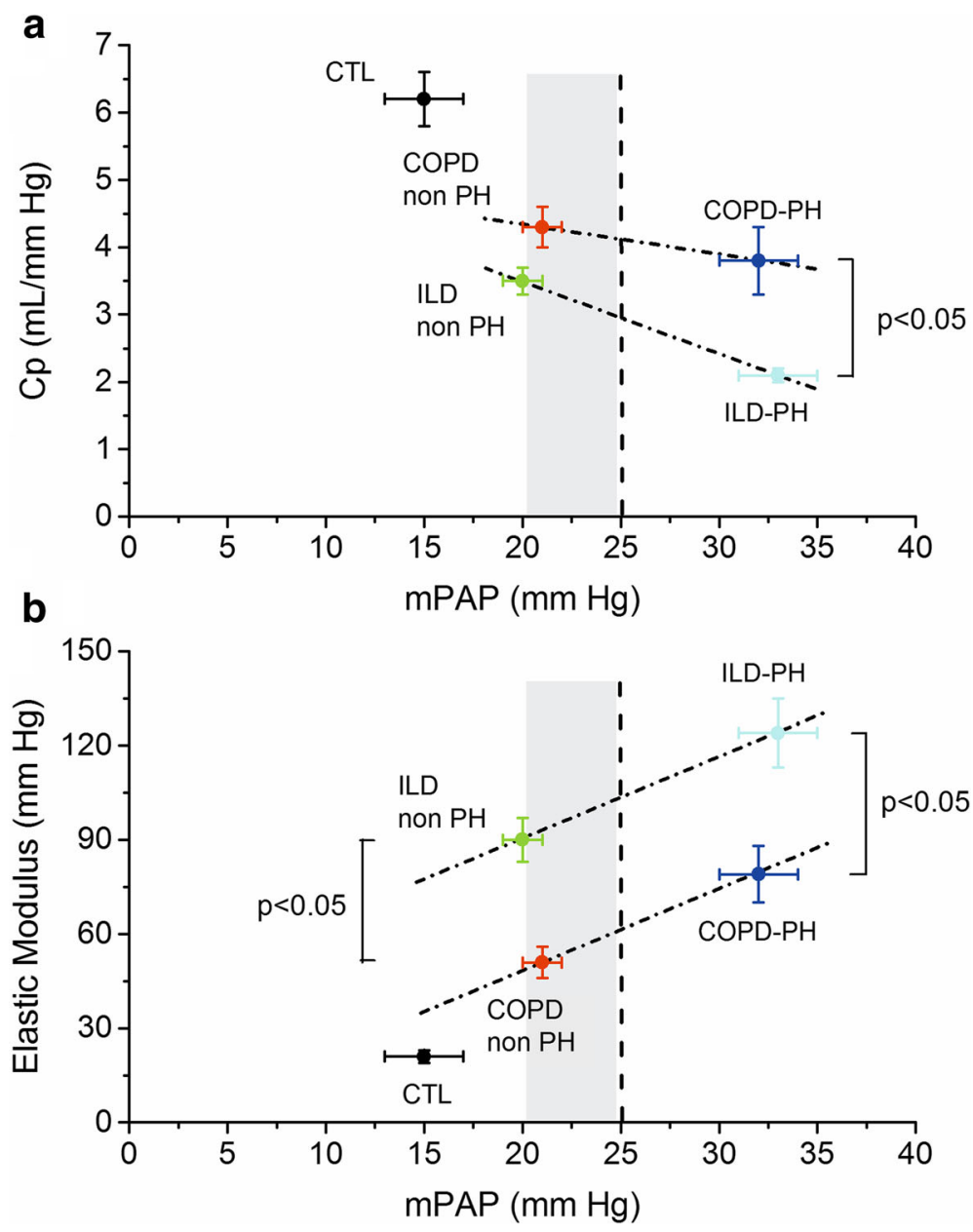

Fig. 3 a Correlation between total pulmonary arterial capacitance (Cp) and mean pulmonary arterial pressure (mPAP) in COPD and ILD patients and b Correlation between elastic modulus (EM) and mPAP in COPD and ILD patients. The dotted line indicates the threshold for PH (mPAP $=25 \mathrm{~mm}$ Hg). The gray rectangle indicates mPAP between $21-24 \mathrm{~mm} \mathrm{Hg}$. CTL Controls

PAWP $>15 \mathrm{mmHg}$ which agrees with the Organ Procurement and Tissue Network (OPTN) database [4].

There are scarce data about the values of EM in healthy subjects. Sanz et al. estimated the main pulmonary artery $(24-26 \mathrm{~mm})$ stiffness by cardiac magnetic resonance imaging obtaining a median value of $32 \mathrm{mmHg}$ [26]. Very recently, Shen et al. using IVUS imaging, assessed the EM of elastic pulmonary arteries of $4.4 \pm 0.2 \mathrm{~mm}$, obtaining a mean value of $44 \pm 4 \mathrm{mmHg}$ [27]. Both, age and range of mPAP of control patients are similar among the studies, excepting the control group of Shen's work that included patients with connective tissue disease without $\mathrm{PH}$, which can explain the higher values of EM secondary to some degree of subclinical vascular remodeling.

One of the main findings of the present study is the observation that patients without $\mathrm{PH}$ presented a significant pulmonary vascular disease with respect to controls. The increase of EM and AWT may indicate an early and significant pulmonary vascular disease in non-PH-lung disease patients. Therefore, the rise in resting mPAP above $25 \mathrm{mmHg}$ is a late marker of the pulmonary vascular disease process [28]. Unlike several studies that attempt to detect some degree of pulmonary vascular disease through the exercise hemodynamic impairment $[25,29,30]$, our results raise the assessment of PA wall behavior as an alternative tool to make the diagnosis of vasculopathy at a preclinical stage [31].

COPD patients showed a lower EM and higher Cp than ILD beyond MPAP; that was associated with a more preserved RC time and a right upward RC plot, such that $\mathrm{Cp}$ was higher for a given TPR. We analyzed the relationship between TPR and Cp and not PVR-Cp, to avoid the potential risk of misleading PAWP measurements [32, 33]. Probably the higher collagen fibers content of the arterial wall associated with the lung tissue fibrotic process could explain the greater stiffness with less thickness of the wall of ILD patients. This is in agreement with Hoffmann et al. [34] who have recently 


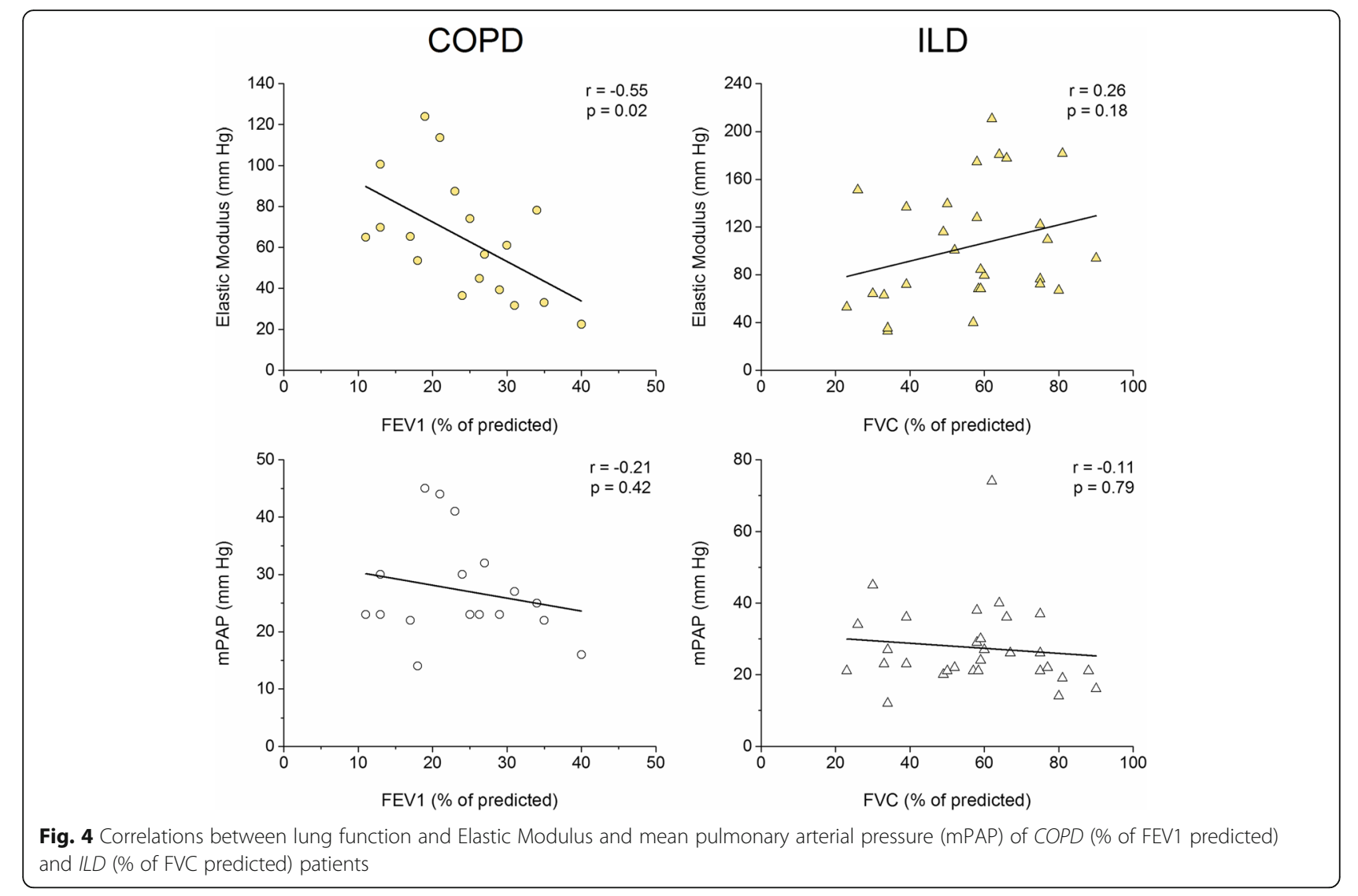

reported that pulmonary arterial remodeling in $\mathrm{PH}-$ COPD and PH-IPF patients is caused by different molecular mechanisms.

The higher RAP and PAWP of COPD than ILD patients could be related to a higher end-expiration intrathoracic pressure [35].

\section{Relationship between pulmonary arterial wall disease and} lung function impairment in COPD and ILD

Multiple mechanisms have been postulated as underlying the development of $\mathrm{PH}$ in COPD but remain incompletely understood [36]. Both hypoxemia and hypercapnia showed a significant correlation with mPAP and EM in our pre-LTx COPD patients. Each one explains about 15 to $30 \%$ of mPAP and EM variation, reflecting the important role of chronic hypoxia and hypercapnia in vascular disease. The absence of correlation between the AWT and mPAP is in accordance to Kubo et al. [37], which reported that in contrast to MPAP at rest, mPAP during exercise was strongly related to pulmonary arterial wall thickness. Finally, the absence or weak correlation between $\mathrm{PH}$ and airway obstruction has been widely known and fits with our results [29, 38]. However, we obtained a strong relationship between FEV1 and EM $(r=-0.55)$, highlighting that airflow limitation may be related to the severity of vasculopathy.
The pathogenesis of PH in ILD is also complex and multifactorial [39]. Correlations between $\mathrm{PaO}_{2}$ and $\mathrm{mPAP}$ and EM in the present study, illustrate the importance of hypoxia in vascular disease. The loss of pulmonary vasculature has been challenged as the main factor for the development of PH in ILD, especially in IPF [40]. Accordingly, previous and current studies did not show a positive relationship between the degree of restrictive physiology and $\mathrm{PH}[7,10]$.

Regarding clinical differences, only ILD patients with $\mathrm{PH}$ have shown a $6 \mathrm{MWT}$ significantly lower than patients without $\mathrm{PH}$, which may be related to the more severe wall remodeling.

\section{Study limitations}

We measured intravascular pulmonary pressures at the end of expiration to minimize the effect of intrathoracic pressure changes during the respiratory cycle since the intra and extrathoracic pressures are equal (pleural pressure is closest to $0=$ atmospheric pressure) and so, intravascular and transmural pressures are similar. Respiratory swings are usually more pronounced in advanced COPD patients, so, intrathoracic pressure is increased during expiration and may be greater than atmospheric pressure. Although averaging intravascular pulmonary pressures over the respiratory cycle may be better estimates of transmural 
pressures, particularly, during exercise in COPD patients [35], we employed end-expiratory measurements based on the recommendations for resting measurements [17]. We cannot discard an expiratory increase of RAP and PAWP that may explain the significantly higher values of the COPD patients [41]. Concomitantly, the pulse PAP and mPAP may decrease during spontaneous expiration in COPD patients at rest [42]. Therefore, we were careful to analyze the $\mathrm{Cp}$ (SV/pulse PAP) and EM (pulse PAP/ IVUSp) for a given mPAP. This allowed to find out there are real differences in pulmonary vascular disease between COPD and ILD.

Although the non-PH control patients were not age- and sex-matched to COPD and ILD patients, age-related pulmonary arterial stiffness begins after $\sim 50$ years old [43].

We evaluate pre-LTx COPD and ILD patients, therefore, our findings cannot apply to all population of COPD and ILD. They also need external validity, since the present study shows the assessment of 46 patients from a single center.

Although the pathologic manifestations of each of the ILDs and their distribution within the lung parenchyma play a role in determining concomitant $\mathrm{PH}$, more than half of PH-ILD patients included corresponding to IPF [8].

The absence of a significant correlation between the EM and the percentage of FVC predicted would allow discarding a prevail effect of the different perivascular pressures exerted by lung tissue connections on the elastic properties of the pulmonary arteries in ILD patients.

\section{Conclusions}

The present study shows that $\mathrm{PH}$ is a late marker of the pulmonary vascular disease process in COPD and ILD candidates for LTx. PA stiffness (assesses by the EM) and the relative area of wall thickness can make the diagnosis of pulmonary vasculopathy at a preclinical stage. Patients with advanced COPD and ILD appear to have a different pulmonary vascular disease. ILD patients showed a worse pulmonary vascular disease with higher EM and lower Cp for a given mPAP. Airflow limitations in COPD but not restriction impairment in ILD patients would be associated with the pulmonary vascular disease. Further research is needed to identify optimal screening methods for pulmonary vascular disease in this patient population and to explore specific therapeutic options.

\footnotetext{
Abbreviations

6MWT: Six-minute walking test; AWT: Area of wall thickness; CO: Cardiac output; COPD: Chronic obstructive pulmonary disease; Cp: Total pulmonary arterial capacitance; DLCO: Diffusion capacity for carbon monoxide; EM: Elastic modulus; FEV1: Forced expiratory volume in one second FVC: Forced vital capacity; ILD: Interstitial lung disease; IVUSp: Intravascular ultrasound pulsatility; LTx: Lung transplantation; mPAP: Mean pulmonary arterial pressure; PAS: Pulmonary arterial stiffness; PAWP: Pulmonary arterial
}

wedge pressure; PH: Pulmonary hypertension; PVR: Pulmonary vascular resistance; RAP: Right atrial pressure; TPR: Total pulmonary resistance

\section{Acknowledgments}

Preliminary data of this study were orally presented in part in the Congress of the European Society of Cardiology Barcelona, Spain. Eur Heart J 2014; 35(Suppl1):176, A923.

Juan C Grignola was supported by CSIC (Comisión Sectorial de Investigación Científica) and is a member (Researcher Level I) of ANII (Agencia Nacional de Investigación e Innovación).

\section{Funding}

Partially support by a grant of Boston Scientific Corporation, USA

\section{Availability of data and materials}

All relevant data generated or analyzed supporting the conclusions of this study are included in this published article.

\section{Authors' contributions}

All authors fulfill the criteria for authorship. ED conceived of the study, participated in its design, conducted the study, analyzed the data and wrote the manuscript. JCG participated in the design of the study, analyzed the data and wrote the manuscript. RA was responsible for data interpretation and manuscript revision. MLM was responsible for patient selection and clinical follow-up. AR was responsible for patient selection and clinical follow-up, and for drafting and revising the manuscript. All authors read and approved the final version of the manuscript. All authors have agreed to authorship and order of authorship for this manuscript.

\section{Competing interests}

None of the authors has any conflicts of interest to disclose.

\section{Consent for publication}

Not applicable.

\section{Ethics approval and consent to participate}

The study protocol was approved by the Institutional Ethics Committee of the Hospital Universitari Vall d'Hebron (Barcelona).

\section{Publisher's Note}

Springer Nature remains neutral with regard to jurisdictional claims in published maps and institutional affiliations.

\section{Author details}

${ }^{1}$ Area del Cor, Hospital Universitari Vall d'Hebron, Barcelona, Spain. 2Physiology Department, School of Medicine, Universitat Autonoma, Barcelona, Spain. ${ }^{3}$ Pathophysiology Department, School of Medicine, Hospital de Clínicas, Universidad de la República, Avda Italia 2870, PC 11600 Montevideo, Uruguay. ${ }^{4}$ Cardiology Department, Hospital Universitario de la Princesa, Universidad Autónoma de Madrid, Madrid, Spain. ${ }^{5}$ Department of Neumology, Hospital Universitari Vall d'Hebron, Barcelona, Spain. ${ }^{6}$ Ciberes, Instituto de Salud Carlos III, Madrid, Spain.

Received: 27 February 2017 Accepted: 27 April 2017

Published online: 06 May 2017

\section{References}

1. Andersen CU, Mellemkjaer S, Nielsen-Kudsk JE, Bendstrup E, Hilberg O, Simonsen U. Pulmonary hypertension in chronic obstructive and interstitial lung diseases. Int J Cardiol. 2013;168:1795-804.

2. Hurdman J, Condliffe R, Elliot CA, Swift A, Rajaram S, Davies C, et al. Pulmonary hypertension in COPD: results from the ASPIRE registry. Eur Respir J. 2013:41:1292-301

3. Shino MY, Lynch JP 3rd, Saggar R, Abtin F, Belperio JA, Saggar R. Pulmonary hypertension complicating interstitial lung disease and COPD. Semin Respir Crit Care Med. 2013:34:600-19.

4. Cuttica MJ, Kalhan R, Shlobin OA, Ahmad S, Gladwin M, Machado RF, et al. Categorization and impact of pulmonary hypertension in patients with advanced COPD. Respir Med. 2010;104:1877-82. 
5. Thabut G, Dauriat G, Stern JB, Logeart D, Levy A, Marrash-Chahla R, et al. Pulmonary hemodynamics in advanced COPD candidates for lung volume reduction surgery or lung transplantation. Chest. 2005;127:1531-6.

6. Hayes Jr D, Black SM, Tobias JD, Mansour HM, Whitson BA. Prevalence of pulmonary hypertension and its influence on survival in patients with advanced chronic obstructive pulmonary disease prior to lung transplantation. COPD. 2016;13:50-6.

7. Lettieri CJ, Nathan SD, Barnett SD, Ahmad S, Shorr AF. Prevalence and outcomes of pulmonary arterial hypertension in advanced idiopathic pulmonary fibrosis. Chest. 2006;129:746-52.

8. Nathan SD. Pulmonary hypertension in interstitial lung disease. Int J Clin Pract Suppl. 2008;62:21-28

9. Nadrous HF, Pellikka PA, Krowka MJ, Swanson KL, Chaowalit N, Decker PA et al. The impact of pulmonary hypertension on survival in patients with idiopathic pulmonary fibrosis. Chest. 2005;128:616S-7S.

10. Shorr AF, Wainright JL, Cors CS, Lettieri CJ, Nathan SD. Pulmonary hypertension in patients with pulmonary fibrosis awaiting lung transplant. Eur Respir J. 2007;30:715-21.

11. Shlobin OA, Brown AW, Nathan SD. Pulmonary hypertension in diffuse parenchymal lung diseases. Chest. 2017;151:204-14.

12. Carlsen J, Hasseriis Andersen $\mathrm{K}$, Boesgaard $\mathrm{S}$, Iversen $\mathrm{M}$, Steinbruchel D, Bogelund AC. Pulmonary arterial lesions in explanted lungs after transplantation correlate with severity of pulmonary hypertension in chronic obstructive pulmonary disease. J Heart Lung Transplant. 2013;32:347-54.

13. Hayes Jr D, Higgins RS, Black SM, Wehr AM, Lehman AM, Kirkby S, et al. Effect of pulmonary hypertension on survival in patients with idiopathic pulmonary fibrosis after lung transplantation: an analysis of the united network of organ sharing registry. J Heart Lung Transplant. 2015;34:430-7.

14. Orens JB, Estenne M, Arcasoy S, Conte JV, Corris P, Egan JJ, et al. International guidelines for the selection of lung transplant candidates: 2006 update- - a consensus report from the pulmonary scientific council of the international society for heart and lung transplantation. J Heart Lung Transplant. 2006;25:745-55.

15. Kovacs G, Avian A, Olschewski A, Olschewski H. Zero reference level for right heart catheterisation. Eur Respir J. 2013;42:1586-94.

16. Dehmer GJ, Firth BG, Hillis LD. Oxygen consumption in adult patients during cardiac catheterization. Clin Cardiol. 1982;5:436-40.

17. Galie N, Humbert M, Vachiery JL, Gibbs S, Lang I, Torbicki A, et al. 2015 esc/ ers guidelines for the diagnosis and treatment of pulmonary hypertension: The joint task force for the diagnosis and treatment of pulmonary hypertension of the european society of cardiology (ESC) and the european respiratory society (ERS): Endorsed by: Association for european paediatric and congenital cardiology (AEPC), international society for heart and lung transplantation (ISHLT). Eur Heart J. 2016;37:67-119.

18. Laurent S, Cockcroft J, Van Bortel L, Boutouyrie P, Giannattasio C, Hayoz D, et al. Expert consensus document on arterial stiffness: methodological issues and clinical applications. Eur Heart J. 2006;27:2588-605.

19. Grignola JC. Is the time constant of the pulmonary circulation truly constant? Eur Respir J. 2014:43:1539-41.

20. Rodes-Cabau J, Domingo E, Roman A, Majo J, Lara B, Padilla F, et al. Intravascular ultrasound of the elastic pulmonary arteries: a new approach for the evaluation of primary pulmonary hypertension. Heart. 2003;89:311-5.

21. Grignola JC, Domingo E, Aguilar R, Vazquez M, Lopez-Messeguer M, Bravo C, et al. Acute absolute vasodilatation is associated with a lower vascular wall stiffness in pulmonary arterial hypertension. Int J Cardiol. 2013;164:227-31.

22. Santana DB, Barra JG, Grignola JC, Gines FF, Armentano RL. Pulmonary artery smooth muscle activation attenuates arterial dysfunction during acute pulmonary hypertension. J Appl Physiol (1985). 2005;98:605-13.

23. Domingo E, Grignola JC, Aguilar R, Montero MA, Arredondo C, Vazquez M, et al. In vivo assessment of pulmonary arterial wall fibrosis by intravascular optical coherence tomography in pulmonary arterial hypertension: a new prognostic marker of adverse clinical follow-up. Open Respir Med J. 2013;7:26-32.

24. Raghu G, Rochwerg B, Zhang Y, Garcia CA, Azuma A, Behr J, et al. An official ATS/ERS/JRS/ALAT clinical practice guideline: treatment of idiopathic pulmonary fibrosis. An update of the 2011 clinical practice guideline. Am J Respir Crit Care Med. 2015:192:e3-e19.

25. Hilde JM, Skjorten I, Hansteen V, Melsom MN, Hisdal J, Humerfelt S, et al. Haemodynamic responses to exercise in patients with COPD. Eur Respir J. 2013;41:1031-41.
26. Sanz J, Kariisa M, Dellegrottaglie S, Prat-Gonzalez S, Garcia MJ, Fuster V, et al. Evaluation of pulmonary artery stiffness in pulmonary hypertension with cardiac magnetic resonance. JACC Cardiovasc Imaging. 2009;2:286-95.

27. Shen JY, Cai ZY, Sun LY, Yang CD, He B. The application of intravascular ultrasound to evaluate pulmonary vascular properties and mortality in patients with pulmonary arterial hypertension. J Am Soc Echocardiogr. 2016; 29:103-11.

28. Lau EM, Manes A, Celermajer DS, Galie N. Early detection of pulmonary vascular disease in pulmonary arterial hypertension: time to move forward. Eur Heart J. 2011;32:2489-98.

29. Portillo K, Torralba Y, Blanco I, Burgos F, Rodriguez-Roisin R, Rios J, et al. Pulmonary hemodynamic profile in chronic obstructive pulmonary disease. Int J Chron Obstruct Pulmon Dis. 2015;10:1313-20.

30. Raghu G, Nathan SD, Behr J, Brown KK, Egan JJ, Kawut SM, et al. Pulmonary hypertension in idiopathic pulmonary fibrosis with mild-to-moderate restriction. Eur Respir J. 2015:46:1370-7.

31. Weir-McCall JR, Struthers AD, Lipworth BJ, Houston JG. The role of pulmonary arterial stiffness in COPD. Respir Med. 2015;109:1381-90.

32. Levarge BL, Pomerantsev E, Channick RN. Reliance on end-expiratory wedge pressure leads to misclassification of pulmonary hypertension. Eur Respir J. 2014:44:425-34.

33. Ryan JJ, Rich JD, Thiruvoipati T, Swamy R, Kim GH, Rich S. Current practice for determining pulmonary capillary wedge pressure predisposes to serious errors in the classification of patients with pulmonary hypertension. Am Heart J. 2012;163:589-94.

34. Hoffmann J, Wilhelm J, Marsh LM, Ghanim B, Klepetko W, Kovacs G, et al. Distinct differences in gene expression patterns in pulmonary arteries of patients with chronic obstructive pulmonary disease and idiopathic pulmonary fibrosis with pulmonary hypertension. Am J Respir Crit Care Med. 2014;190:98-111.

35. Boerrigter BG, Waxman AB, Westerhof N, Vonk-Noordegraaf A, Systrom DM. Measuring central pulmonary pressures during exercise in COPD: how to cope with respiratory effects. Eur Respir J. 2014;43:1316-25.

36. Hostler J, Brown AW, Sherner J, King CS, Nathan SD. Pulmonary hypertension in COPD. Eur Respir Monogr. 2013;59:189-205.

37. Kubo K, Ge RL, Koizumi T, Fujimoto K, Yamanda T, Haniuda M, et al. Pulmonary artery remodeling modifies pulmonary hypertension during exercise in severe emphysema. Respir Physiol. 2000;120:71-9.

38. Andersen $\mathrm{KH}$, Iversen M, Kjaergaard J, Mortensen J, Nielsen-Kudsk JE,

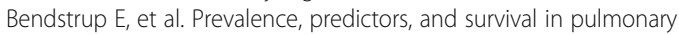
hypertension related to end-stage chronic obstructive pulmonary disease. J Heart Lung Transplant. 2012;31:373-80.

39. Nathan SD, Cottin V. Pulmonary hypertension in patients with idiopatic pulmonary fibrosis. Eur Respir Monogr. 2012;57:148-60.

40. Farkas L, Gauldie J, Voelkel NF, Kolb M. Pulmonary hypertension and idiopathic pulmonary fibrosis: a tale of angiogenesis, apoptosis, and growth factors. Am J Respir Cell Mol Biol. 2011;45:1-15.

41. Rosenkranz S, Preston IR. Right heart catheterisation: best practice and pitfalls in pulmonary hypertension. Eur Respir Rev. 2015;24:642-52.

42. Boerrigter B, Trip P, Bogaard HJ, Groepenhoff H, Oosterveer F, Westerhof N, et al. Right atrial pressure affects the interaction between lung mechanics and right ventricular function in spontaneously breathing COPD patients. Plos One. 2012;7:e30208.

43. Oliveira RK, Agarwal M, Tracy JA, Karin AL, Opotowsky AR, Waxman AB, et al. Age-related upper limits of normal for maximum upright exercise pulmonary haemodynamics. Eur Respir J. 2016;47:1179-88.

\section{Submit your next manuscript to BioMed Central and we will help you at every step:}

- We accept pre-submission inquiries

- Our selector tool helps you to find the most relevant journal

- We provide round the clock customer support

- Convenient online submission

- Thorough peer review

- Inclusion in PubMed and all major indexing services

- Maximum visibility for your research

Submit your manuscript at www.biomedcentral.com/submit 